\title{
Understanding the intergenerational transmission of violence
}

\author{
N Woollett, ${ }^{1}$ MA (Psychology, Art Therapy); K Thomson, ${ }^{2}$ MA (Social Work) \\ ${ }^{1}$ School of Clinical Medicine and School of Public Health, Faculty of Health Sciences, University of the Witwatersrand, Johannesburg, South Africa \\ ${ }^{2}$ Wits Reproductive Health and HIV Institute, Faculty of Health Sciences, University of the Witwatersrand, Johannesburg, South Africa
}

Corresponding author: N Woollett (woollettn@gmail.com)

Intimate partner violence is a major public health and human rights issue in South Africa. This violence tends to run in families and generations, with little change over time and devastating consequences at individual, family and community levels. Understanding the mechanisms for intergenerational transmission of violence may offer important clues for prevention and intervention to halt this recurrence. Health professionals are well placed to identify patients at risk and intervene in families characterised by interpersonal violence.

S Afr Med J 2016;106(11):1068-1070. DOI:10.7196/SAMJ.2016.v106i11.12065

\section{How does violence beget violence?}

Intimate partner violence (IPV) is one of the most common forms of violence against women and children worldwide. ${ }^{[1]}$ Violence against children, adolescents and women has similar consequences for physical health, mental health and social functioning. Experiencing multiple forms of violence in childhood and adolescence (e.g. child maltreatment, exposure to IPV, bullying, dating violence) raises the risk of trauma and other negative health and social outcomes compared with experiencing just one form. ${ }^{[2]}$ But why is it that those who experience violence early in life are likely to repeat and re-experience it, and why is it so difficult to change this trajectory?

\section{Pertinent theories and concepts}

Bandura's social learning theor $y^{[3]}$ has often been applied to studying the intergenerational transmission of family violence and IPV. ${ }^{[4-6]}$ This theory posits that behaviours are often learnt from one's environment, and that the family system plays a pivotal role in tutoring. Children inevitably mimic and learn interpersonal skills from their parents, and this theory explains why children who grow up witnessing and experiencing IPV are more likely to be either perpetrators or victims later in their own relationships. ${ }^{[4]}$ Children in these situations learn that violence is normal, appropriate, inescapable and inevitable in intimate relationships. Conflict tends to result in violence, aggression is rewarded, and strong rationalisations for violent behaviour tend to develop. The skills of effective and safe conflict resolution are not acquired and violent conflict resolution is likely to be repeated with no prosocial alternatives.

Bowlby's attachment theory ${ }^{[7]}$ emphasises that the initial relationship between infant and caregiver serves as the foundation for an infant's mental health and all future attachment and relationships in life. For children growing up in violent households, expectations of security are shattered, as their protectors become their attackers and there is nowhere to turn for help. If parents are not only the source of external danger but are simultaneously absent in their duty to protect, those you love become those you fear. This leads to great distress and an inability to regulate overwhelming emotion ${ }^{[8]}$ People with a history of child abuse expect others to be hostile, rejecting, and unavailable, and they therefore respond to others in a way that is consistent with their expectations or they behave in a manner that elicits these familiar responses in others. ${ }^{[7]}$ This experience is the result of early attachment relationships with abusive caregivers, as the parent-child attachment relationship is the prototype for later relationships. ${ }^{[9]}$ As Bowlby states, 'hurt people hurt people'. Attachment theory holds that individuals who have experienced maltreatment or attachmentrelated difficulties are more likely to report problems with regard to trust and closeness in subsequent relationships, and to express hostility and anger towards others in a variety of ways. ${ }^{[10]}$

The mental health aspects of experiencing this violence should not be underestimated. Those who are consistently exposed to violence are likely to suffer from depression and post-traumatic stress disorder (PTSD) ${ }^{[11,12]}$ The concepts of re-enactment or repetition compulsion are implicated in the intergenerational transmission of trauma, which is the consequence of violence. Trauma tends to be repeated on behavioural, emotional, physiological and neuro-endocrinological levels and many traumatised people expose themselves, seemingly compulsively, to situations reminiscent of the original trauma. ${ }^{[13]}$ These behavioural re-enactments are rarely consciously understood to be related to earlier life experiences. Freud thought that the aim of repetition was to gain mastery over the original trauma(s), but clinical experience has shown that this rarely happens. Instead, repetition causes further suffering for victims and/or for people in their surroundings. ${ }^{[13]}$ Reiker and Carmen ${ }^{[14]}$ point out that confrontations with violence challenge one's most basic assumptions about the self as invulnerable and intrinsically worthy, and about the world as orderly, safe and just. After abuse, the victim's view of the self and the world can never be the same again: it must be reconstructed to incorporate the abuse experience. Assuming responsibility for the abuse/violence ('it was my fault') allows feelings of helplessness to be replaced with an illusion of control. Children are even more likely to blame themselves when they experience violence at the hands of their loved ones. Anger directed against the self or others is typically a central problem in the lives of people who have been violated. Reiker and Carmen ${ }^{[14]}$ conclude that this 'acting out' is seldom understood by either victims or clinicians as being a repetitive re-enactment of real events from the past.

These issues are framed by the concept of displaced aggression (Fig. 1). Displaced aggression can occur when someone cannot aggress towards the source of incitements or provocation, and instead takes it out on some- 


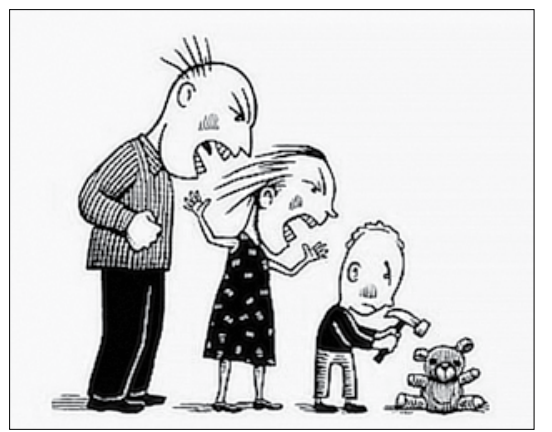

Fig. 1. Displaced aggression (courtesy of Kweykway Consulting, Canada).

thing/someone else and behaves aggressively towards another individual who had nothing to do with the initial conflict. In other words, when a violent partner with more power and control aggresses towards you and you are not able to meet that aggression in an equal manner, you take your anger to where you have significant power and control and repeat what was done to you. These cycles of aggression are typical in homes defined by IPV. Victims become perpetrators through frustration, with inadequate conflict resolution skills, the inability to express anger in prosocial ways and have legitimate and strong aggressive impulses.

All these concepts should be comprehended within a context of continuous traumatic stress, which is described as the experience of repeated traumatic events (e.g. IPV) against a background of ongoing danger (e.g. community violence); therefore, the threat is current and real; safety is difficult to establish; there is a lack of trust in state systems of protection and help; and there is a threat to family and community networks and systems. ${ }^{[15,16]}$ Violent events are understood within this social construct and there is an expectation that trauma is part of life as opposed to an 'unexpected' event. ${ }^{[17]}$ The threat and ongoing reality of trauma affect how people live and cope, both individually and collectively. Violence and trauma are therefore not only about the set of events experienced, but are deeply ingrained in a person's history, identity, values and traditions. ${ }^{[18]}$

\section{Clinical recommend- ations}

Parents/caregivers are the primary socialisation agents involved in children's emotional and social development. Children learn by watching their parents/caregivers and imitating their behaviour from infancy through young adulthood. Poor parenting skills are a key risk factor for child maltreatment. Parenting programmes that help parents negotiate and learn safer discipline strategies and conflict resolution skills are indicated. Parents need alternatives to be better role models for their children and 'unlearn' unhealthy behaviours. There is a growing body of evidence to suggest that these programmes are sustainable, feasible and acceptable in low- and middle-income contexts. ${ }^{[19]}$ Parenting programmes also contribute to reducing family stress and maternal mental ill-health, ${ }^{[20]}$ and improve parentchild attachment and relationships. ${ }^{[21]}$

Exploring mother-infant prenatal attachment is an important focus in understanding the intergenerational consequences of trauma. Expectant mothers with a history of interpersonal trauma report significantly lower prenatal attachment development with their unborn child than expectant mothers with no such history. ${ }^{[22]}$ Screening for violence during pregnancy and intervening in antenatal environments would have a great impact on curbing the intergenerational transmission of violence and improving attachment between mother and infant.

There is evidence of a direct relationship between maternal functioning and child behavioural functioning. ${ }^{[6]}$ Therefore, interventions that decrease maternal mental health problems can be expected to have a secondary effect on the mental and behavioural functioning of their children. As mothers learn to improve coping strategies, so do their children. Interestingly, this is a bi-directional relationship, with recent evidence suggesting that cognitive behaviour therapy for child PTSD is directly related to improvements in maternal depressive symptoms. ${ }^{[23]}$ Research indicates that in the context of IPV, interventions for children are more effective when their focus is on the dyad of mother and child, instead of child alone. ${ }^{[24]}$ As such, treatment needs to be focused on the maternal-child dyad for optimum results, and improved attachment for both.

Mental healthcare for those experiencing violence is highly recommended, especially trauma-focused cognitive behaviour therapy that is recognised as the gold standard in trauma treatment. ${ }^{[25]}$ Gaining control over one's current life, rather than repeating trauma in action, mood or somatic states, is the goal of treatment. In addition, helping patients consider 'novel' situations of safety in a relationship is a treatment goal, recognising that for many of them novel stimuli can cause heightened arousal and for those already living in states of heightened hyperarousal (those with PTSD) this is to be avoided to manage their anxiety. High arousal causes people to engage in familiar behaviour, regardless of the rewards. Many victims unconsciously choose partners that are considered 'normal' to their experience to avoid managing this dynamic.
The ongoing risk of IPV is a formidable obstacle to effective treatment of victims. When psychological treatment is provided after the traumatic situation no longer exists, the goals of treatment involve placing the traumatic experience into perspective by helping a person gain control over the overwhelming emotions evoked by the memory of the event, and achieving a differentiation between remembering and reliving by stressing differences between past and present circumstances and increasing the person's awareness of the current, safer surroundings. These goals are not realistic and may be counterproductive when conditions of violence leading to traumatic stress responses are ongoing, as hypervigilance and other traumatic responses may be adaptive but costly mechanisms to increase personal safety. When providing medical or psychological treatment, it is important to ask about familial and community contexts. The primary focus in these situations should be on conditions that increase safety and reduce risk. This focus promotes progress towards another key goal of fostering an increased capacity to respond realistically to threat. ${ }^{[8]}$

Family violence in childhood, whether through witnessing or direct experience, may trigger a cycle of adversities, including re-victimisation, mental health problems and other life difficulties. ${ }^{[10]}$ It is clear that in the South African (SA) context, experience of IPV is strongly linked to incident HIV infection; ${ }^{[26]}$ therefore, treating IPV may have benefits to HIV incidence and prevalence. Early detection and treatment of violence against young people and children have the potential to interrupt and prevent the recurrences of violence, incident HIV in high-risk groups, and adverse psychological impacts for children and adolescents.

The transmission of interpersonal violence takes shape as adolescents begin to experiment within their own relationships as they get older. Adolescents are at high risk of IPV.$^{[27]}$ Their young age and relative inexperience can limit their power in relationships and incur risk, particularly for females involved with older men. ${ }^{[27]}$ Abuse during this time can also set young women on a trajectory for future violence and sexual risk behaviour. This age group is open to change and is flexible in trying new things. This developmental opportunity offers a window for alternative relationships and personal reflection that adults need to recognise. Interventions levelled at this patient population are urgently required. Health infrastructures designed for youth must recognise and actively anticipate that their patient populations will incur victims. 
Prevention strategies directed towards violence experienced by couples and children/adolescents should be integrated into public health and primary care planning. If a woman, for example, is identified as experiencing IPV, an opportunity also exists to identify a maltreated child and vice versa. Also, mental health problems identified should alert health professionals to the possibility of violence in the family or in the teen relationship because of their potential association with history for such violence. Asking a potential victim directly about these issues should be part of routine clinical practice.

Educational programmes that target both genders to discuss gender inequality in public and private spheres and how violence leads to unhealthy outcomes for all are required. While gender socialisation starts at birth, early adolescence is a critical point of intensification in personal gender attitudes, as puberty reshapes male and female self-perceptions as well as social expectations from others (e.g. family members, peers). Early adolescence is therefore seen as a unique time to address gender attitudes before they become more solidified. ${ }^{[28]} \mathrm{An}$ opportunity to do this exists at different healthcare levels.

Another key focus should be men, as they are more likely to be violent offenders and men of all ages play a significant role in tolerating IPV, thereby perpetuating intergenerational transmission.

\section{Conclusion}

Healthcare facilities are key points of contact in the community. They provide services and are influenced by events and experiences of the individuals and communities they serve. Health professionals are therefore powerfully placed to identify and address issues of violence in patients. Historically, violence against women and that against children sectors have worked in isolation. Violence affects the entire community, and its impact on physical and mental health is evident. For better health outcomes, greater recognition of the similarities in violence outcomes, shared risk factors and intergenerational effects for populations is needed. A closer collaboration of sectors would lead to a more meaningful and integrated policy response and healthcare service. Partnership across sectors is highly recommended. ${ }^{[2]}$

1. Devries KM, Kishor S, Johnson H, et al. Intimate partner violence during pregnancy: Analysis of prevalence data from 19 countries. Reprod Health Matters 2010;18(36):158-170. DOI:10.1016/s09688080(10)36533-

2. Guedes A, Bott S, Garcia-Moreno C, Colombini M. Bridging the gaps: A global review of intersections of violence against women and violence against children. Glob Health Action 2016;9:1-15. DOI:10.3402/gha.v9.31516

3. Bandura AJ. Social Learning Theory. Englewood Cliffs, NJ: Prentice Hall, 1977. DOI:10.1177/ 105960117700200317
4. Islam TM, Tareque I, Tiedt AD, Hoque H. The intergenerational transmission of intimate partner violence in Bangladesh. Glob Health Action 2014;7:1-11. DOI:10.3402/gha.v7.23591

5. Mandal M, Hindin M. Keeping it in the family: Intergenerational transmission of violence in Cebu, 5. Mandal M, Hindin MJ. Keeping it in the family: Intergenerational transmission of violen
Philippines. Matern Child Health J 2015;19(3):598-605. DOI:10.1007/s10995-014-1544-6

6. McFarlane J, Symes L, Binder BK, Maddoux J, Paulson R. Maternal-child dyads of functioning 6. McFarlane J, Symes L, Binder BK, Maddoux J, Paulson R. Maternal-child dyads of functioning:
The intergenerational impact of violence against women and children. Matern Child Health J The intergenerational impact of violence against wo
2014;18(9):2236-2243. DOI:10.1007/s10995-014-1473-4

7. Bowlby J. Attachment and Loss. Vol. 3. New York: Basic Books, 1980. DOI:10.1017//50021932000013596 8. Lieberman A. Ghosts and angels: Intergenerational patterns in the transmission and treatment of the traumatic sequelae of domestic violence. Inf Mental Health J 2007;28(4):422-439. DOI:10.1002/imhj.20145 9. Hines DA, Saudino KJ. Intergenerational transmission of intimate partner violence: A behavioral genetic perspective. Trauma Violence Abuse 2002;3(3):210-225. DOI:10.1177/15248380020033004

10. Jirapramukpitak T, Harpham T, Prince M. Family violence and its 'adversity package': A common survey of family violence and adverse mental outcomes among young people. Soc Psychiatry Psychiat Epidemiol 2011;46(9):825-831. DOI:10.1007/s00127-010-0252-9

11. Devries KM, Mak JY, Bacchus LJ, et al. Intimate partner violence and incident depressive symptoms and suicide attempts: A systematic review of longitudinal studies. PLoS Med 2013;10(5):e1001439. DOI:10.1371/journal.pmed.1001439

12. Bennice JA, Resick PA, Mechanic M, Austin M. The relative effects of intimate partner physical and sexual violence on post-traumatic stress disorder symptomatology. Violence Vict J 2003;18(1):87-94 DOI:10.1891/vivi.2003.18.1.87

13. Van der Kolk B. The compulsion to repeat the trauma: Reenactment, revictimization and masochism. Psych Clin N Am 1989;12(2):389-411.

14. Reiker PP, Carmen E. The victim to patient process: The disconfirmation and transformation of abuse Am J Orthopsychiatry 1986;56(3):360-370. DOI:10.1111/j.1939-0025.1986.tb03469.x

15. Murphy M. When the trauma goes on. Child Care Prac 2004;10(2):185-191. DOI:10.1080/1357527 0410001693394

16. Kaminer D, Eagle G, Crawford-Browne S. Continuous traumatic stress as a mental and Kaminer D, Eagle G, Crawford-Browne S. Continuous traumatic stress as a mental and
physical health challenge: Case studies from South Africa. J Health Psych 2016;21(1):1-12. DOI: $10.1177 / 1359105316642831$

17. Thomson K. Exploring the experience of community health workers operating in contexts where trauma and its exposure are continuous. MA thesis. Johannesburg: University of the Witwatersrand, 2014

18. Higson-Smith C. Supporting Communities Affected by Violence. Oxford, UK: Oxfam, 2002 DOI:10.3362/9780855988579

19. Knerr W, Gardner F, Cluver L. Improving positive parenting skills and reducing harsh and abusive parenting in low- and middle-income countries: A systematic review. Prev Sci 2013;14(4):352-363. DOI:10.1007/s11121-012-0314-1

20. Barlow J, Smailagic N, Huband N, Rollof V, Bennet C. Group-based parenting programmes for improving parental psychosocial health. Cochrane Database Syst Rev 2012;(6):CD002020. DOI:10.1002/14651858.cd002020.pub3

21. Cooper P, Tomlinson M, Swartz L, et al. Improving quality of mother-infant relationship and infant attachment in a socio-economically deprived community in South Africa. BMJ 2009;338:b974. DOI: $10.1136 / \mathrm{bmi} . b 1858$

22. Schwerdtfeger KM, Nelson Goff BS. Intergenerational transmission of trauma: Exploring the motherinfant prenatal attachment. J Traum Stress 2007;20(1):39-51. DOI:10.1002/jts.20179

23. Neill EL, Weems CF, Scheeringa MS. CBT for child PTSD is associated with reductions in maternal depression: Evidence for bidirectional effects. J Clin Child Adolesc Psychol 2016:1-11. DOI:10.1080/ 15374416.2016.1212359

24. Graham-Bermann SA, Miller-Graff LE, Howell KH, Grogan-Kaylor A. An efficacy trial of an intervention program for children exposed to intimate partner violence. Child Psychol Hum Dev 2015;46(6):927-939. DOI:10.1007/s10578-015-0532-4

25. Foa EB, Keane TM, Friedman MJ, Cohen, JA, eds. Effective Treatments for PTSD: Practical Guidelines from the International Society for Traumatic Stress Studies. 2nd ed. New York: Guildford Press, 2009: 491-507. DOI:10.1002/pon.660

26. Li Y, Marshall CM, Rees HC, et al. Intimate partner violence and HIV infection among women: A Li Y, Marshall CM, Rees HC, et al. Intimate partner violence and HIV infection among women:
systematic review and meta-analysis. J Int AIDS Soc 2015;17(1):1-12. DOI:10.7448/ias.17.1.18845

27. Decker MR, Peitzmeier S, Olumide A, et al. Prevalence and health impact of intimate partner violence and non-partner sexual violence among female adolescents aged 15 - 19 years in vulnerable urban environments: A multi-country study. J Adolesc Health 2014;55(6):s58-s67. DOI:10.1016/, jadohealth.2014.08.022

28. Kagesten A, Gibbs S, Blum RW, et al. Understanding factors that shape gender attitudes in earl adolescence globally: A mixed methods systematic review. PLoS ONE 2016;11(6):e0157805. DOI:10.1371/journal.pone. 0157805 